\author{
О.О. Челпанова, В.А. Турчина \\ Дніпровський національний університет імені Олеся Гончара
}

\title{
УЗАГАЛЬНЕННЯ АНОМАЛЬНИХ ВИПАДКІВ У ЗАДАЧАХ УПОРЯДКУВАННЯ
}

У даній роботі проводиться аналіз однісї з задач дискретної оптимізації, а саме: задачі побудови паралельних упорядкувань мінімальної довжини. Досліджуються випадки появи аномальних погіршень у розв'язках задачі при логічному покращенню початкових умов.

Ключові слова: аномалії, оптимальне паралельне упорядкування, мінімальна довжина упорядкування.

\author{
O.O. Chelpanova, V.A.Turchyna
}

Oles Honchar Dnipro National University

\section{GENERALIZATION OF ANOMALOUS CASES IN ORDERING PROBLEMS}

The solution of NP-complete problems is important in the study of communication networks, control systems, chemical and genetic structures, electrical circuits, design of complex communication systems, in the study of transport and information flows and others. Moreover, increasingly relevant are the applied tasks, which are reduced to the construction of schedules for a set of partially ordered works.

That is, some optimization problems on graphs can be classified as schedule theory problems. In the language of ordering theory, the value of the objective function, namely the length or width of the ordering, is minimized on a given graph.

From a practical point of view, problems are more common when the works have different execution times. Therefore, in this paper we consider the generalization of the problem of minimizing the ordering length. Examining the exact and approximate methods of solving such problems, we can conclude that loosening the constraints, increasing the width or reducing the time of work leads to a decrease in the value of the length of the ordering. However, in the practical study of the problem it turns out that the variation of any of the parameters, including the list of priorities, probably leads to an anomaly, namely: an increase in the length of the ordering. Anomalies are cases where seemingly intuitive conclusions are not confirmed.

Cases of simultaneous fulfillment of two or more conditions, which should improve the result, are investigated and by examples it is illustrated how the result, on the contrary, worsens. Thus, the length of the optimal orderings, provided that the initial conditions are improved, becomes larger than the length of the optimal ordering for the original graph and conditions.

An urgent task is to select subclasses of problems for which anomalies will not affect the optimality of the solution and subclasses of problems, when they will exactly affect.

Keywords: anomalies, optimal parallel ordering, minimum ordering length.

(C) Челпанова О.О., Турчина В.А., 2021 


\author{
О.А. Челпанова, В.А. Турчина \\ Днипровский национальный университет имени Олеся Гончара
}

\title{
ОБОБЩЕНИЕ АНОМАЛЬНЫХ СЛУЧАЕВ В ЗАДАЧАХ УПОРЯДОЧЕНИЯ
}

В данной работе проводится анализ одной из задач дискретной оптимизации, а именно: построения параллельных упорядочений минимальной длины. Исследуются случаи появления аномальных ухудшений в решениях задачи при логическом улучшении начальных условий.

Ключевые слова: аномалии, оптимальное параллельное упорядочение, минимальная длина упорядочения.

Вступ. Експоненційна складність задач дискретної оптимізації, що відносяться до класу NP-важких [3], вказує на необхідність або розробляти ефективні наближені алгоритми, або виділяти підкласи задач, для яких удається отримати точні розв'язки за поліноміальний час. У даній роботі розглядається одна із таких постановок, до якої можуть бути зведені деякі практичні задачі. Зокрема, до них відносяться: дослідження комунікаційних мереж, систем управління, хімічних і генетичних структур, електричних ланцюгів, проектування складних систем зв'язку, дослідження транспортних та інформаційних потоків та інші.

Зупинимося на тому підкласі задач, що зводяться до побудови розкладів для множини частково упорядкованих робіт. Крім отримання методів розв'язання цих задач, потребують вивчення і так звані аномальні випадки, що можуть виникати при їх розв'язанні.

Постановка задачі. Нехай для виконання роботи $i$ потрібний один виконавець, $i=1,2, \ldots, n$, де $n$ - кількість робіт. Задаються наступні умови:

1) кожен виконавець може виконувати будь-яку роботу;

2) тривалість виконання роботи $i$ не залежить від виконавця і дорівнює однаковому проміжку часу для всіх робіт;

3) можливо паралельне виконання декількох робіт;

4) на виконання деяких робіт можуть накладатися технологічні обмеження (наприклад, робота $j$ не може бути почата доти, поки не завершена робота $i$ );

Розклад, який не порушує технологічних обмежень називається допустимим.

Допустимий розклад, що має задану довжину і потребує мінімальної кількості виконавців або при заданій кількості виконавців має мінімальну довжину, називається оптимальним [2].

Нехай $m$ - кількість виконавців, $t$ - довжина розкладу. Сформулюємо дві основні задачі.

Задача 1 . За заданим значенням $t$ побудувати допустимий розклад з мінімальним значенням $m$.

Задача 2. За заданим значенням $m$ побудувати допустимий розклад з мінімальним значенням $t$. 
Сформулюємо ці задачі на мові теорії упорядкувань [2].

Нехай $G=\{V, U\}-$ орграф, $V=\{1,2, . ., n\}-$ множина вершин, $U-$ множина дуг. Тоді, $G$ - модель обмежень на порядок виконання робіт, $V$ - множина робіт, $U$ - множина технологічних обмежень, а $(i, j) \epsilon U$ означає, що робота $i$ повинна бути виконана до початку виконання роботи $j$.

Упорядкуванням $S$ скінченої множини $V$, що складається з $n$ елементів, називається розміщення цих елементів на $n$-місцях таким чином, що кожний елемент розташовується на одному місці.

Довжиною $l(S)$ упорядкування $S$ називається кількість непорожніх місць упорядкування $S$.

Нехай $S[p]-$ множина елементів з $V$, які розташовані в упорядкуванні $S$ на місці $p$ [4].

Шириною $h(S)$ упорядкування $S$ називається кількість елементів найбільшої за потужністю множини $S[p]$.

Упорядкування $S$ множини $V$ вершин орграфа $G$ називається паралельним упорядкуванням вершин орграфа $G$, якщо з того, що $(i, j) \epsilon U$, випливає, що $i$ розташовується в $S$ лівіше $j$. Тобто, якщо $i \epsilon S[p]$ та $j \epsilon S[q]$, то $p<q$.

Паралельне упорядкування називається оптимальним, якщо воно має мінімальну ширину при заданій довжині або мінімальну довжину при заданій ширині.

Тобто, задачі 1 і 2 можна сформулювати наступним чином:

Задача 1 . По заданому графу $G$ і заданому значенню $l$ треба побудувати паралельне упорядкування $S$ мінімальної ширини.

Задача 2 . По заданому графу $G$ і заданому значенню $h$ треба побудувати паралельне упорядкування мінімальної довжини.

Ці задачі позначають відповідно $S(G, l, h)$ та $S(G, h, l)$.

До точних методів розв'язання задач паралельного упорядкування відносяться методи, засновані на схемах перебору (метод повного перебору, метод гілок та меж). Якщо задача дискретної оптимізації належить до класу $N P$-повних, то виділяють підкласи задач, для яких вдається отримати точні алгоритми поліноміальної складності [3]. До такого випадку відносяться задачі, для яких на кожне місце упорядкування можливо поставити не більше двох вершин, та коли граф $G$ - це кореневе дерево або ліс.

3 практичної точки зору більш поширеними є задачі, коли роботи мають різний час виконання. Тому, розглянемо узагальнення задачі 2 , коли задано зважений граф. Вага вершини $i$ - це час $\tau_{i}$ виконання відповідної роботи 3 номером $i$.

Досліджуючи точні та наближені методи розв'язання таких задач, можна зробити висновок, що послаблення обмежень, збільшення ширини $h$ або зменшення часу виконання робіт призводить до зменшення значення $l$. Але, при практичному дослідженні задачі виявляється, що варіювання будь-якого 3 параметрів, включаючи і список пріоритетів, імовірно призводить до виникнення аномалії, а саме: збільшення довжини упорядкування. Під аномаліями розуміються випадки, коли здається інтуїтивно зрозумілі висновки не 
підтверджуються. Грехем [1] розглянув задачу, коли задана скінчена множина робіт та скінчена множина виконавців. На порядок виконання робіт задані технологічні обмеження та відомий час виконання кожної роботи. Крім того, він досліджував випадки, коли задані бажані пріорітети виконання робіт. При аналізі цієї задачі такий аномальний ефект може бути виявлений при наступних змінах параметрів:

1) зменшенні часу робіт;

2) послабленні обмежень на порядок робіт;

3) збільшенні кількості виконавців;

4) зміні порядку пріорітетів виконання робіт.

Розглянемо появу аномалій багатопроцесорних розкладів на прикладі.

Приклад 1. Задано граф $G_{1}$ (рис.1), список пріоритетів $L=(1,2,3,4,5,6,7,8,9,10), h=3$. Вага кожної вершини дорівнює $\tau_{i}$. Кожна вершина на рисунку позначається як «i $\tau_{i} »$ («номер вершини/вага вершини»).
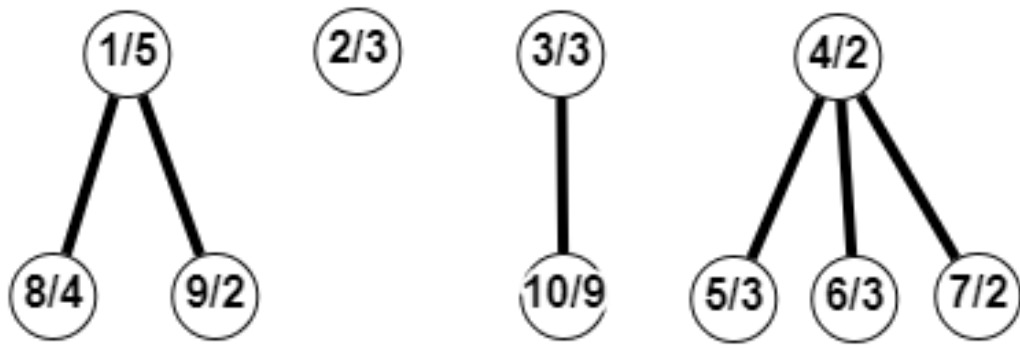

Рис. 1. Граф $G_{1}$

Знайдемо оптимальне упорядкування та мінімальну довжину $l$.

Оптимальне упорядкуван ня для графа $G_{1}$

Таблиця 1

\begin{tabular}{|c|c|c|c|c|c|c|c|c|c|c|c|}
\hline 1 & 1 & 1 & 1 & 1 & 5 & 5 & 5 & 7 & 7 & 9 & 9 \\
\hline 2 & 2 & 2 & 4 & 4 & 6 & 6 & 6 & 8 & 8 & 8 & 8 \\
\hline 3 & 3 & 3 & 10 & 10 & 10 & 10 & 10 & 10 & 10 & 10 & 10 \\
\hline
\end{tabular}

Довжина $l=12$.

Розглянемо випадки появи аномалій:

1) Зменшуємо час виконання робіт. Задаємо вагу деяких вершин наступним чином:

$$
\tau_{i}^{r}=\tau_{i}-k,
$$

де $\tau_{i}^{F}-$ нова вага кожної вершини, $k=\overline{1,2}$. Позначаємо граф як $G_{2}$ (рис.2). 

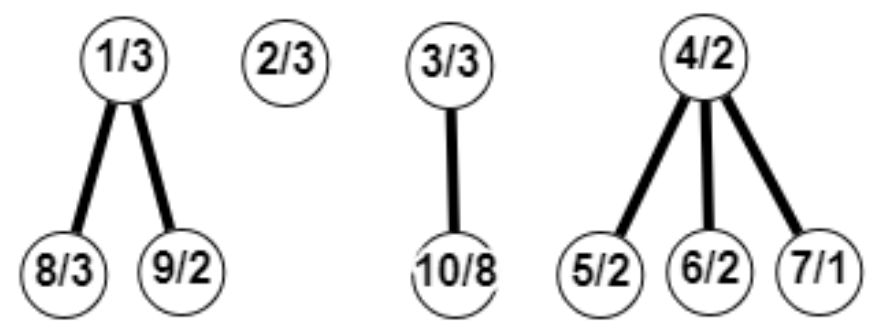

Рис. 2. Граф $G_{2}$

Будуємо оптимальне упорядкування (табл.2):

Оптимальне упорядкування для графа $G_{2}$

Таблиця 2

\begin{tabular}{|l|l|l|l|l|l|l|l|l|l|l|l|l|l|l|}
\hline 1 & 1 & 1 & 4 & 4 & 5 & 5 & 10 & 10 & 10 & 10 & 10 & 10 & 10 & 10 \\
\hline 2 & 2 & 2 & 8 & 8 & 8 & 7 & & & & & & & & \\
\hline 3 & 3 & 3 & 9 & 9 & 6 & 6 & & & & & & & & \\
\hline
\end{tabular}

Довжина $l=15$. Тобто, при зменшенні часу виконання деяких робіт, загальний час виконання усіх робіт навпаки помітно збільшився.

2) Послабимо обмеження на порядок виконання робіт. Нехай задано граф $G_{3}$ (рис.3).
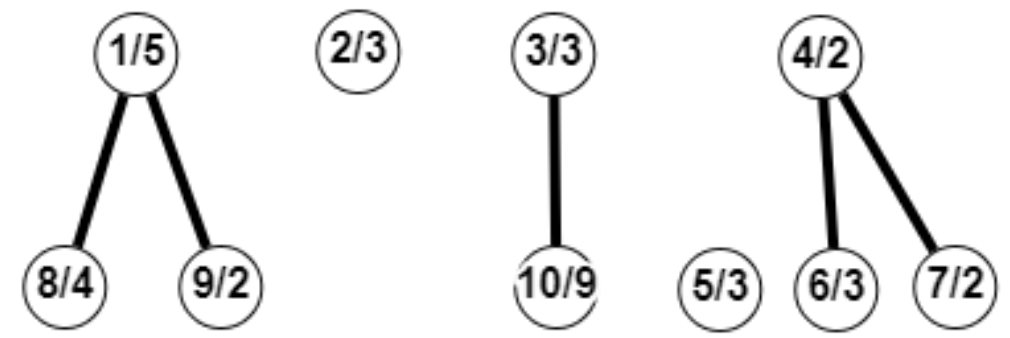

Рис. 3. Граф $G_{3}$

Знайдемо оптимальне упорядкування та мінімальну довжину $l$ для цього випадку.

Таблиця 3

Оптимальне упорядкування для графа $G_{3}$

\begin{tabular}{|l|l|l|l|l|l|l|l|l|l|l|l|l|l|l|l|l|}
\hline 1 & 1 & 1 & 1 & 1 & 6 & 6 & 6 & 10 & 10 & 10 & 10 & 10 & 10 & 10 & 10 & 10 \\
\hline 2 & 2 & 2 & 4 & 4 & 7 & 7 & 9 & 9 & & & & & & & & \\
\hline 3 & 3 & 3 & 5 & 5 & 5 & 8 & 8 & 8 & 8 & & & & & & & \\
\hline
\end{tabular}

Довжина $l=17$, маємо погіршення результату. 
3) Збільшуємо кількість виконавців. $h^{r}=h+1, h^{t}=4$. Граф $G_{l}$ (рис.1) не змінюється.

Таблиця 4

Оптимальне упорядкування для графа $G_{1}$ при $h=4$

\begin{tabular}{|l|l|l|l|l|c|c|c|c|c|c|c|c|c|}
\hline 1 & 1 & 1 & 1 & 1 & 8 & 8 & 8 & 8 & & & & & \\
\hline 2 & 2 & 2 & 6 & 6 & 6 & & & & & & & & \\
\hline 3 & 3 & 3 & 7 & 7 & 9 & 9 & & & & & & & \\
\hline 4 & 4 & 5 & 5 & 5 & 10 & 10 & 10 & 10 & 10 & 10 & 10 & 10 & 10 \\
\hline
\end{tabular}

Довжина $l=14$, знову виникає аномалія.

4) Змінюємо порядок виконання робіт. Нехай $L^{\prime}=(4,1,2,3,5,6,7,10,8,9)$, граф $G_{l}$ (рис.1) залишається без змін.

Оптимальне упорядкування для графа $G_{1}$ при $L^{g}$

Таблиця 5

\begin{tabular}{|l|l|l|l|l|l|c|c|c|c|c|c|c|c|c|}
\hline 4 & 4 & 3 & 3 & 3 & 6 & 6 & 6 & 9 & 9 & & & & & \\
\hline 1 & 1 & 1 & 1 & 1 & 7 & 7 & 8 & 8 & 8 & & & & & \\
\hline 2 & 2 & 2 & 5 & 5 & 5 & 10 & 10 & 10 & 10 & 10 & 10 & 10 & 10 & 10 \\
\hline
\end{tabular}

Довжина $l=15$, тобто інтуїтивно вдала зміна порядку робіт знову призвела до збільшення загального часу виконання робіт.

Тому, виникає питання, чи будуть мати місце аномалії, якщо розглядати узагальнення декількох випадків, наприклад:

1) одночасного збільшення кількості ресурсів та зміни порядку виконання робіт;

2) одночасного зменшення часу виконання завдань та послаблення технологічних обмежень;

3) послаблення технологічних обмежень та збільшення кількості ресурсів.

Розглянемо перший випадок для графа $G_{1}$ (рис.1), список приоритетів $L=(1,2,3,4,5,6,7,8,9,10)$, ширина упорядкування $h=3$. Збільшуємо кількість виконавців $h^{t}=h+1, h^{t}=4$. Нехай $L^{t}=(1,2,3,4,5,6,7,10,9,8)$.

Побудуємо оптимальне упорядкування та знайдемо мінімальну довжину для заданих умов.

Таблиця 6

Оптимальне упорядкування для графа $G_{1}$ при $L^{z}, h=4$

\begin{tabular}{|l|l|l|l|l|l|l|l|l|l|l|l|l|l|}
\hline 1 & 1 & 1 & 1 & 1 & 10 & 10 & 10 & 10 & 10 & 10 & 10 & 10 & 10 \\
\hline 2 & 2 & 2 & 6 & 6 & 6 & & & & & & & & \\
\hline 3 & 3 & 3 & 7 & 7 & 9 & 9 & & & & & & & \\
\hline 4 & 4 & 5 & 5 & 5 & 8 & 8 & 8 & 8 & & & & & \\
\hline
\end{tabular}

$l=14$. 
Розглянемо випадок 2. Зменшуємо час виконання робіт. Задаємо вагу усіх вершин наступним чином:

$$
\tau_{i}^{x}=\tau_{i}-1,
$$

де $\tau_{i}^{F}-$ нова вага кожної вершини. Послаблюємо обмеження, видаляючи дугу між вершинами $i=4$ та $i=5$. Позначаємо граф як $G_{4}$ (рис.4).
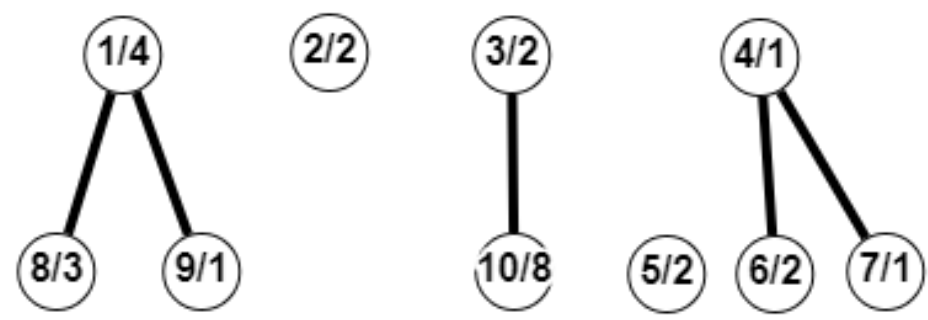

Рис. 4. Граф $G_{4}$

За заданими умовами будуємо оптимальне упорядкування (табл.7).

Оптимальне упорядкування графа для $G_{4}$

Таблиця 7

\begin{tabular}{|l|l|l|l|l|l|l|l|l|l|l|l|l|}
\hline 1 & 1 & 1 & 1 & 7 & 9 & & & & & & & \\
\hline 2 & 2 & 4 & 6 & 6 & 10 & 10 & 10 & 10 & 10 & 10 & 10 & 10 \\
\hline 3 & 3 & 5 & 5 & 8 & 8 & 8 & & & & & & \\
\hline
\end{tabular}

Довжина упорядкування збільшується, $l=13$.

Розглянемо третій приклад. Збільшуємо кількість виконавців та послаблюємо обмеження. Отримуємо граф $G_{5}$ (рис.5).
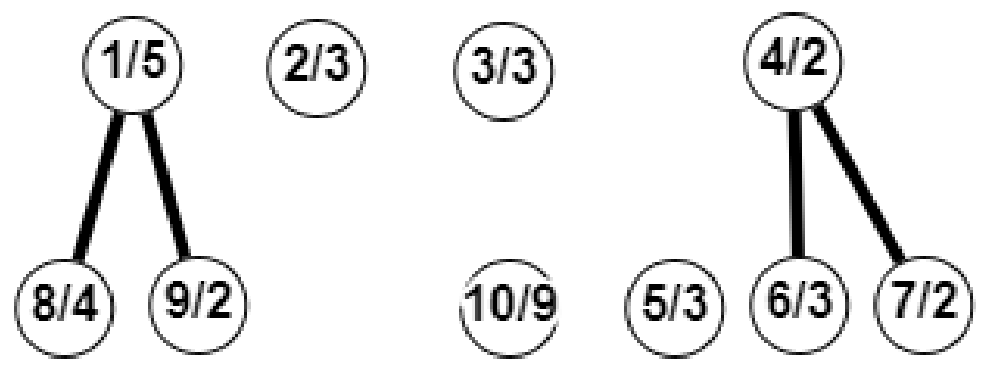

Рис. 5. Граф $G_{5}$

Для заданих умов оптимальне паралельне упорядкування матиме наступний вигляд: 
Оптимальне упорядкування для графа $G_{5}$ при $h=4$

\begin{tabular}{|l|l|l|l|l|l|l|l|l|l|l|l|l|l|l|}
\hline 1 & 1 & 1 & 1 & 1 & 8 & 8 & 8 & 8 & & & & & & \\
\hline 2 & 2 & 2 & 6 & 6 & 6 & 10 & 10 & 10 & 10 & 10 & 10 & 10 & 10 & 10 \\
\hline 3 & 3 & 3 & 7 & 7 & 9 & 9 & & & & & & & & \\
\hline 4 & 4 & 5 & 5 & 5 & & & & & & & & & & \\
\hline
\end{tabular}

Тут також ми спостерігаємо аномалію. Довжина $l=15$, що є на 25 \% більше від довжини оптимального упорядкування для графа $G_{l}$.

Після дослідження та підтвердження припущень щодо виникнення аномалій при одночасному виконанню двох умов, логічним виникає питання чи будуть мати місце аномалії при одночасному покращенню трьох параметрів, запропонованих Грехемом.

Для графа $G_{1}$ розглянемо випадок одночасного збільшення ширини $h^{r}=h+1, h^{r}=4$, зміни списку пріоритетів $L^{t}=(1,2,3,4,5,6,7,10,9,8)$ та послаблення технологічних обмежень, як показано на графі $G_{3}$ (рис. 3 ).

Будуємо оптимальне упорядкування (табл. 9).

Таблиця 9

Оптимальне упорядкування для графа $G_{3}$. Випадок виконання трьох умов

\begin{tabular}{|l|l|l|l|l|l|l|l|l|l|l|l|l|l|l|}
\hline 1 & 1 & 1 & 1 & 1 & 10 & 10 & 10 & 10 & 10 & 10 & 10 & 10 & 10 & \\
\hline 2 & 2 & 2 & 6 & 6 & 6 & & & & & & & & & \\
\hline 3 & 3 & 3 & 7 & 7 & 9 & 9 & & & & & & & & \\
\hline 4 & 4 & 5 & 5 & 5 & 8 & 8 & 8 & 8 & & & & & & \\
\hline
\end{tabular}

Значення довжини не покращується, довжина $l=14$.

Висновки. Зрозуміло, що випадки появи аномальних погіршень рішення задачі при логічному покращенню та спрощенню умов, матимуть місце не для всіх графів. Тому, актуальним питанням $є$ виділення підкласів задач, для яких вказані аномалії не вплинуть на оптимальність розв'язку та підкласи задач, коли вони точно будуть впливати.

\section{Бібліографічні посилання}

1. Graham R. L. Bounds on multiprocessing timing anomalies // SIAM J. Appl. Math., 1969. V. 17. P. 416-429.

2. Бурдюк В.Я. Алгоритмы параллельного упорядочения: Учебное пособие / В.Я. Бурдюк, В.А. Турчина. - Д.: ДГУ, 1985. 84c.

3. Гэри М. Вычислительные машины и труднорешаемые задачи / М. Гэри, Д. Джонсон. М.: Мир, 1982. 416 c.

4. Хохлюк В.И. Методы дискретной оптимизации: Учебное пособие. / В.И. Хохлюк. Новосибирск: Новосиб. гос. ун-т, 2013. 154 с.

Надійшла до редколегії 14.07. 2021. 